\title{
Human Behaviour and Economic Growth: A Psychocultural Perspective on Local and Regional Development
}

\author{
Robert Huggins \\ School of Planning and Geography, Cardiff University, Glamorgan Building, King Edward VII \\ Avenue, Cardiff, CF10 3WA, UK \\ E-mail: $\underline{\text { HugginsR@cardiff.ac.uk }}$ \\ Tel: +44 (0)2920876006 \\ Piers Thompson \\ Nottingham Business School, Nottingham Trent University, $8^{\text {th }}$ Floor Newton Building, 50 \\ Shakespeare Street, Nottingham, NG1 4FQ, UK \\ E-mail: piers.thompson@ntu.ac.uk \\ Tel: +44 (0) 1158482143 \\ Martin Obschonka \\ Australian Centre for Entrepreneurship Research, QUT Business School, Queensland \\ University of Technology, Gardens Point, 2 George St, Brisbane, QLD 4000, Australia \\ E-mail: martin.obschonka@qut.edu.au
}

\begin{abstract}
A renewed emphasis on behavioural traits has emerged as a means of explaining regional and local differences in economic performance and development. Given this, the aim of this study is to identify distinct local psychocultural behavioural profiles and to examine the extent to which these are associated with economic growth. Combining theories of community culture and personality psychology into a holistic spatially-oriented perspective, the paper argues that the types of human behaviour found across local places emerges from the co-evolution of cultural and personality factors. An empirical analysis of localities in Great Britain identifies and explores three underlying psychocultural profiles: Diverse Extraversion; Inclusive Amenability and Individual Commitment. It is found that inclusive amenable and individually committed psychocultural behaviour generally appear to hold back local economic growth, with the exception of recessionary periods. The reverse relationship is somewhat the case for diverse extravert behaviour. It is concluded that a better understanding of the holistic relationship and co-evolution of the cultural and psychological behavioural make-up of localities and regions has the potential to provide new insights into expected development outcomes as well as the forms of policy intervention that are required within regions and localities, each of which has its own individual psychocultural character.
\end{abstract}

Key words: behaviour; personality psychology; community culture; Big Five personality traits; economic growth; localities.

Please cite this article as follows:

Huggins, R. Thompson, P. and Obschonka, M. (2018) 'Human Behaviour and Economic Growth: A Psychocultural Perspective on Local and Regional Development', Environment and Planning A, doi: 10.1177/0308518X18778035

This is a manuscript of an article accepted of publication by Sage Journals in Environment and Planning A on $3^{\text {rd }}$ April 2018, available online:

http://dx.doi.org/10.1177/0308518X18778035 


\title{
Human Behaviour and Economic Growth: A Psychocultural Perspective on Local and Regional Development
}

\begin{abstract}
A renewed emphasis on behavioural traits has emerged as a means of explaining regional and local differences in economic performance and development. Given this, the aim of this study is to identify distinct local psychocultural behavioural profiles and to examine the extent to which these are associated with economic growth. Combining theories of community culture and personality psychology into a holistic spatially-oriented perspective, the paper argues that the types of human behaviour found across local places emerges from the co-evolution of cultural and personality factors. An empirical analysis of localities in Great Britain identifies and explores three underlying psychocultural profiles: Diverse Extraversion; Inclusive Amenability and Individual Commitment. It is found that inclusive amenable and individually committed psychocultural behaviour generally appear to hold back local economic growth, with the exception of recessionary periods. The reverse relationship is somewhat the case for diverse extravert behaviour. It is concluded that a better understanding of the holistic relationship and co-evolution of the cultural and psychological behavioural make-up of localities and regions has the potential to provide new insights into expected development outcomes as well as the forms of policy intervention that are required within regions and localities, each of which has its own individual psychocultural character.
\end{abstract}

\section{Introduction}

Studies continue to find considerable and persistent differences in economic performance and development between and within regions and localities in nations (Guiso et al., 2008; Huggins and Thompson, 2016). These differences are often not possible to explain through differences in traditional inputs such as labour and capital, even when accounting for human capital and knowledge production (Obschonka et al., 2015). This remains the case despite the burgeoning of theoretical literature on regional and local economic growth and related concepts such as competitiveness and resilience (Martin and Sunley, 2017). Unfortunately, the presence of competing models inevitably may be leading to uncertainty relating to the appropriate variables to include in models for localities, regions or specific groups of regions (Crespo Cuaresma et al., 2014). Understandably, this gives rise to a lack of consensus with 
regard to interventions that should be pursued, with instances of policy being perceived to be running ahead of theory (Martin and Sunley, 2015).

In recent years, a new emphasis on pyschoculture has entered the equation in terms of efforts to seek to explain regional and local differences in performance and development (Huggins and Thompson, 2017), with studies such as Tabellini (2010) finding a connection between culture and institutions and the economic development of regions, whilst others including Huggins and Thompson (2015a; 2016) finding a link between socio-spatial community culture and a noted driver of economic performance, i.e. entrepreneurial activity. In this case, community culture may influence how resources such as physical capital, labour and human capital are utilised (Rauch et al., 2013), and even where traditional and some non-traditional inputs, such as knowledge flows, are held constant there are still considerable differences in economic growth rates across places (Davidsson and Wiklund, 1997). As such, it is important to consider these local or regional differences when determining policy, and therefore a more place-based policy may be more likely to be appropriate than place-neutral policies (Barca et al., 2012).

The aim of this study is to adopt a holistic perspective at the local level that considers specific configurations of cultural features, which in combination influence the outputs attained (Rentfrow et al., 2013). In particular, it combines theories of community culture and personality psychology into a holistic spatially-oriented perspective in order to identify the distinct psychocultural behavioural profiles present in localities across Great Britain. This psychocultural behavioural approach draws upon the interaction between the community culture apparent in these localities, which generate the social norms that influence the behaviour of individuals (Scott, 2008), and the personality traits of individuals located in these places. With regard to the latter, the inclusion of personality traits within the rubric of geographic psychocultural behaviour is a recognition of the growing research stream in 
psychology that utilises large personality sets in order to show the distinctiveness and meaningfulness of regional and local personality differences (Rentfrow et al., 2013; 2015; Obschonka et al., 2015; 2016). However, an outstanding gap in our knowledge is the extent to which the clustering of community culture and personality traits influence factors such as economic growth. In essence, the study seeks to identify the typical pattern of personality traits and culture that together builds the functional psychocultural character of a locality, and to test the extent to which this is associated with economic outcomes. In order to examine this relationship, the study attempts to answer the following research questions using data from Great Britain. (1) To what extent are local psychocultural profiles related to local development as captured by economic growth? (2) Do these psychocultural profiles influence economic development of localities differently depending on the point within the economic cycle? (3) Is there an interaction between the psychocultural profile of places and processes of local economic convergence?

The study suggests that if there is a process of co-evolution between community culture and personality traits within a particular locality or region, then certain combinations of each will impact upon the economic performance of these places. Initially, the paper examines the existing literature to suggest how community culture and personality traits may co-evolve. Data is then used from Great Britain to examine whether this is the case and whether the distribution of psycho-cultural behaviour varies across local areas. The paper then seeks to establish whether any particular forms of psychocultural behaviour are associated with greater economic growth.

\section{Community Culture, Personality Psychology and Economic Development}

Studies have frequently found a role for personality traits, culture and institutions in determining economic growth, but equally it should be noted that there are important 
differences between each of these factors. In fundamental terms, these factors work at different levels of aggregation. Whilst personality traits are individually held, community culture relates to the shared values, beliefs and expectations of a group (Van Maanen and Schein, 1979). Alternatively, Hofstede (1980) refers to systems of meaning within and across ascribed and acquired social groups, and collective programming of the mind. Institutions on the other hand have been described as the rules of the game (Hwang and Powell, 2005). In the literature stemming from economic and political science, in particular, institutions act through rules, procedures and agreements (North 1990).

It is becoming increasingly recognised that the individual actions leading to places being better positioned to take higher economic development roads are encouraged or limited by local and regional influences, where these influences are formed by the dominant cultural traits embedded in local communities (Storper, 2013). The role of institutions in development has been acknowledged and it is, therefore, a fairly reasonable assumption to extend this to cultural influences. As well as the incentives and constraints that institutions and culture provide, they will themselves also be reflective of human agency (Bristow and Healy, 2014). As such, a growing number of studies have considered the link between community culture and economic activities, and the resultant rate of economic development (Huggins and Thompson, 2014; Tubadji and Nijkamp, 2015a; b).

One of the most commonly analysed aspects of culture is social cohesion, which reflects the complexity of the cultural-economic growth relationship. Whilst studies such as Easterly et al. (2006) have found social cohesion, as captured by a lack of ethnic fractionalisation, to be positively associated with economic growth, other studies have found the opposite. Greater social cohesion is thought to reduce transaction costs and improve cooperation and information flows (Putnam et al., 1993; Beugelsdijk and van Schaik, 2005; Kwon and Adler, 2014). This is achieved through the generation of greater trust from the development of social 
capital (Dasgupta, 2011). Institutions associated with publically funded education can have a key role in developing the common social norms that benefit society (Gradstein and Justman, 2000). This cooperation and collaboration are considered to be key components of the innovative activities required to achieve lasting economic growth (Rutten and Boekema, 2007). It is, therefore, no surprise that where deep divisions exist within communities these are often associated with poorer economic performance (Aghion et al., 2004). However, social cohesion can also have a downside, where it leads to rent seeking behaviour of dominant groups and produces insider-outsider problems (Rodríguez-Pose and Storper, 2006).

Alongside the role of social cohesion, another group of studies inspired by Florida (2002a) have found that open tolerant societies grow faster, reflecting the attraction of both conventional human capital and a greater presence of the creative class (Florida et al., 2008). This may allow access to more ideas, but can also help exploit the knowledge held and developed within an area as more diverse sets of skills become available. Studies also suggest that migrants are better placed to see the opportunities available by using a fresh pair of eyes and drawing on international networks (Levie, 2007). Rodríguez-Pose and Hardy (2015) examine the link between diversity and entrepreneurial activity, and find that place of birth diversity, rather than ethnic background, has the strongest relationship with entrepreneurship.

Overall, empirical studies have provided mixed evidence, with some support for stronger economic growth in cases where greater membership of community groups reflects cohesion (Knack and Keefer, 1997; Zak and Knack, 2001; Guiso et al., 2004), while others find little connection between stronger more closely bonded societies and greater economic success (Rodríguez-Pose, 2001). Other studies find evidence of a relationship between social capital and improved performance at the level of individual firms, but there is less evidence when considering a region or locality as a whole (Cooke et al., 2005). A potential explanation for 
the mixed results found by studies is that it is not always appropriate to study culture purely in terms of one aspect, but rather through specific combinations. For example, social cohesion might have positive effects when combined with an openness to ideas, but equally could form a further barrier when combined with a limited acceptance of ideas from outside a community (Adler and Kwon, 2000). An important distinction can be made between bonding and bridging social capital (Putnam, 2000). Both forms of social capital are likely to have costs in terms of formation and maintenance, and whereas bridging social capital may reduce rent seeking activities and provide access to valuable knowledge to achieve economic objectives, bonding social capital's may be better placed to achieve non-materialistic objectives, potentially at the expense of growth (Beugelsdijk and Smulders, 2003). This is one of the limitations of existing studies that the present work seeks to go beyond.

An alternative explanation is that concepts such as social capital are often explored as unidimensional constructs, but in reality have different components that should considered from a holistic perspective. Seminal work by Coleman (1988) and Putnam et al. (1993) on conceptualising social capital recognises three components, social trust, social norms and associational activity, but analyse one single measure of overall social capital (Bjørnshov, 2006). The argument is often made that repeated interactions through associational activity leads to greater social trust, i.e. a relational approach must be adopted (Rutten and Boekema, 2012), but others suggest that at best this is only weakly related to generalised trust (Knack and Keefer, 1997). As such, Bjørnskov (2006) finds that only social trust is related to outcomes such as improved governance and life satisfaction. On the other hand, some studies find that associational activity, and the weak ties this generates, are of particular importance for economic activity related to innovation (Hauser et al., 2007). However, the form of social capital and associated policy interventions could also vary depending on the type of innovation sought, e.g. traditional, hidden or social (Murphy et al., 2016). Other cultural traits 
that are also found to be linked to economic growth are: individualism, or a lack of collectivism (Gorodnichenko and Roland, 2016; Huggins and Thompson, 2016); and more masculine cultures (Huggins and Thompson, 2016). Gorodnichenko and Roland (2016) find innovation and growth to be higher in those countries associated with individualism. In particular, they suggest that the social status rewards associated with innovation are greater in such societies.

In parallel with theoretical developments concerning the influence of culture on economic growth, another stream of literature has considered how individual behaviour may have an impact at the aggregate level (Obschonka et al., 2013; Stuetzer et al., 2016). There have long been studies within psychology and personality science with regard to the different personality traits possessed by individuals (Cattell, 1943). One of the most commonly utilised approaches is that associated with the Big Five framework, which consists of extraversion, agreeableness, conscientiousness, neuroticism, and openness (Costa and McCrae, 1992). More extravert individuals exhibit higher levels of sociability and energy. Agreeableness capturing prosocial behaviour is linked to social capital and reduced crime (Rentfrow et al., 2008; Rentfrow, 2010). Conscientiousness is associated with individual levels of organisation and self-discipline. Neuroticism reflects differences in anxiety and depression. Openness is associated with individual differences in curiosity and liberal values. Whilst such measures have traditionally been used to examine how particular personalities can lead to particular behaviour and outcomes at the individual level (Judge et al., 1999), the use of large surveys has allowed much bigger databases to be created comparing personality traits across nations (Schmitt et al., 2007). The size of these surveys has allowed an examination of the distribution of these personality traits across different areas of countries such as the USA (Rentfrow et al., 2009; Rentfrow, 2010) and UK (Rentfrow et al., 2015). 
Unlike cultural norms, which are formed at the group level, these personality traits are based on the individual, but where a place has a relatively larger proportion of particular types of personality present, this may affect local or regional factors such as economic or other quality of life outcomes (Obschonka et al., 2013). Rentfrow et al. (2015) find a positive link between economic prosperity and openness and extraversion, whilst conscientiousness displays a negative association. This is interesting, as Lee (2017) finds that conscientiousness in England and Wales is positively associated with innovation as captured by patenting activity. Regardless, there is a recognition that activities such as innovation and entrepreneurship are likely to be promoted by certain cultures or the presence of particular personality traits (Wyrwich, 2015). As with community culture, a majority of work has examined the impact of particular individual personality traits in isolation on a variety of outcomes. However, in order to move beyond these single variables perspective at the local or regional level, there is a need for a more holistic conceptualisation of these factors (Rentfrow et al., 2013), especially as certain configurations of traits have been found to be good predictors of developmental outcomes such as: achievement at school (Hart et al., 2003); development of social support networks (Caspi, 2000); older age health such as prevalence of strokes and heart disease (Chapman and Goldberg, 2011); and likelihood of having spells in unemployment (Caspi, 2000). Understandably where such configurations are more prevalent in a locality or region it would be expected that community outcomes will differ.

Rentfrow et al.'s (2013) study introduced a spatially-oriented perspective on personality psychology by finding three spatial clusters across the US described as: friendly and conventional; relaxed and creative; and temperamental and uninhibited. This study is one of the first to develop a holistic spatially-oriented psychological perspective, and found numerous associations between the geographic clustering of personality types and economic 
outcomes. However, it does not account for the role of local cultural aspects when examining these relationships.

\section{Towards A Holistic Perspective on the Psychoculture of Place}

When examining the culture and personality traits present within a locality or region, studies have frequently noted that the two are likely to be closely linked. In their study of voting patterns, Rentfrow et al. (2009) suggest a bi-directional relationship between culture and the presence of particular personality traits. This is understandable given research indicating that in the long-term the genetic and cultural evolution of humans is interactive, i.e. culturalgenetic co-evolution (Van den Bergh and Stagl, 2003). This co-evolution can be related to theories of 'generation' and 'collective memory', or as 'generational units' of meaningful collectives that move through time with high degrees of self-awareness (Lippmann and Aldrich, 2016). Given the above, it can be proposed that it is this interactive and co-evolving psychocultural behaviour, rather than an individual trait or aspect of community culture, which is most likely to be important for economic growth. In order to understand this coevolution it is necessary to examine the mechanisms that have been suggested by previous studies that link the development of one to the other. First, those links stemming from culture and influencing personality are examined, and then those running in the opposite direction. Initially, it should be recognised that personality traits are usually found to be stable or slowly evolving at the individual level (Cobb-Clark and Schurer, 2012).

Rentfrow et al. (2015) highlight three routes that may result in differences in personality developing within countries or even regions. These three mechanisms act through: traditions and social norms; physical environment; and selective migration. With regard to the first of these, community culture provides the social norms that may influence an individual's attitude and behaviour (Hofstede and McCrae, 2004). This can include a pressure to conform 
and fit with the prevailing culture, for example, exposure to a more diverse and tolerant population is found to be positively associated with greater acceptance and openness (Pettigrew and Tropp, 2006). Similarly, a prevailing culture that adheres to social rules is strongly linked to an individual's habits and perceptions of others (Bourgeois and Bowen, 2001).

The second mechanism, physical environment is less likely to be directly linked to community culture. As such, this mechanism can work on personality traits (van der Vliert, 2009), as well as the community culture present (Huggins and Thompson, 2016). For example, agreeableness and conscientious may develop as a coping mechanism for more challenging environments (Steel et al., 2008; Jokela et al., 2015). The third mechanism, selective migration, may also be linked to community culture, whereby those individuals who do migrate basing their choice of location on community cultures that provide a good psychological fit with their own personality traits. Indeed, Jokela et al.’s (2015) finding that those with high openness seek out communities with similar traits is consistent with this proposition.

As well as community culture influencing the personalities of those residing in these communities, it is just as plausible that personality at an individual level will affect the development of community culture through its influence on social norms and attitudes. Although a particular community culture may attract or dissuade the inward migration of certain personalities, once within the locality such personality traits may influence community culture evolution. This may be a slow process, but where, for example, a less socially cohesive community culture attracts individuals of a more extravert and less agreeable nature, such individuals are likely to reinforce the reproduction of existing social norms associated with a less cohesive local community culture. The potential for a reinforcing pattern to development is captured by studies such as Florida (2002b), which 
suggests that the presence of bohemians attracts other high skilled individuals. This presumably operates through those pursuing a bohemian lifestyle, with these individuals helping to generate a tolerant community culture that does not exclude outsiders, particularly more extravert individuals who are willing to explore new ideas.

At the other end of the spectrum, where agreeableness is higher, it is suggested that outward migration is reduced (Jokela et al., 2008; Boneva et al., 1998). This helps to generate a more socially cohesive society, potentially to such an extent that outsiders are excluded (Rodríguez-Pose and Storper, 2006). Societies with more bonding social capital have been found to place greater weight on non-materialistic outcomes and place greater value on family lives (Beugelsdijk and Smulders, 2003), which may become engrained in the social norms of the community culture present. Finally, to complete the analysis of the relationships between local personality and community culture it is important to reiterate the role played by institutions. It has been recognised that collective community culture at an informal level is both an influence on endogenously formed formal institutions (Easterley et al., 2006), and can also compensate where formal institutions are weaker (Gorodnichenko and Roland, 2016). Therefore, it is clear that institutions should be incorporated into empirical analyses. Whilst the empirical part of this study adopts a quantitative approach, the endogenous and holistic perspective provides an evolutionary and pluralistic element to the analysis that goes beyond the single variable approach employed by many quantitative studies (Pike et al. 2016). In terms of the mechanisms and processes through which the psychocultural profile of a place may impact upon development outcomes, it can be proposed that some psychocultural profiles may better facilitate the type of entrepreneurship and innovation that leads to economic growth (Hauser et al., 2007; Stuetzer et al., 2016; Wyrwich, 2015).

The key point to stress, however, is that it is the combined and holistic psychological and cultural profile of localities and regions that is likely to shape these mechanisms and 
processes, and subsequent development outcomes. Furthermore, the influence of the psychocultural profile of a place on economic outcomes may have a temporal variance, particularly with regard to macroeconomic cycles. In times of widespread high rates of economic growth some local profiles may be better suited and positioned to capitalise on these positive economic conditions. Conversely, in times of recession and austerity, other types of local pyschocultural profiles may be better placed to foster resilience within a local economy (Martin and Sunley, 2017).

\section{Data and Methods}

This section outlines the methodological approach adopted to quantitatively analyse how cultural and personality factors within a locality combine to form its holistic psychocultural profile, and to examine how this profile may relate to economic success.

\section{Units of Analysis and Key Measures}

The empirical analysis of this study focuses on Great Britain, with a number of studies noting that there are considerable and persistent differences in the economic success of localities within Britain (Gardiner et al., 2013). The main spatial level of analysis used in this study is the local authority district level, which offers an appropriate social habitat to understand the relationship between psychological, cultural and economic behaviour (Rentfrow, Jokela, and Lamb, 2015; Tabellini, 2010; Huggins and Thompson, 2016). In total there are 380 localities at this level of spatial disaggregation, and due to some missing data, 374 are examined in this is study (see the Online Appendix for further detail).

The measures of economic performance utilised here are growth in Gross Value Added (GVA) and Gross Disposable Household Income (GDHI). Alternative measures could have been justified as more appropriately capturing the economic well-being of those living in the 
localities such as unemployment rates, average earnings, or measures that also account for the distribution of earnings. It could be argued that alternative measures capturing well-being or happiness directly may be even more appropriate (Pike, Rodríguez-Pose, and Tomaney, 2007). However, GVA, and at a national level GDP, are the most commonly targeted measures of economic success. GDHI does, however, provide a measure of economic success that may more strongly capture the welfare of the resident populations after accounting for taxes and government transfers. The growth in these values is investigated for the period 2002 to 2015 where all data required is available in a consistent manner. As the Great Recession occurred within this period, the study also considers a number of sub-periods: prior to the recession 2002 to 2007; the main Great Recession period and downturn 2007 to 2011; and the initial recovery 2011 to 2015 (see the Online Appendix for further detail). Although personality and culture are suggested to evolve slowly (Cobb-Clark and Schurer, 2012), examining this post recessionary period benefits from having greater confidence in the direction of causality, as the majority of data used to create the personality and cultural variables is from the beginning of this period.

The measures of personality utilised in this study are the Big Five Personality dimensions: extraversion; agreeableness, conscientiousness, neuroticism (emotional stability), and openness (John et al., 2008). The Big Five Personality traits were developed from analysis of natural language terms people use to describe themselves, building on the early work of Cattell (1943). Tupes and Christal (1961) used a variety of samples to examine the relationships between those traits identified by earlier work and concluded that they could be captured within five factors. As such, the Big Five allow previously developed measures of personality to be integrated within them to provide a set of clear and easy to interpret measures (John and Srivastava, 1999). Therefore, this study adopts the Big Five Personality approach to capturing personality traits due to the wide spread use of these measures in the 
empirical literature on personality traits. This wide usage has ensured that considerable work has been undertaken in developing and testing instruments to capture personality traits of this kind (Credé et al. 2012). The personality trait data used in this analysis was captured through the British Broadcasting Corporation's (BBC) Lab UK website as part of the BBC's and University of Cambridge's Big Personality Test project (see the Online Appendix for further detail). The socio-spatial community culture measures are based on those used by Huggins and Thompson (2016), which are indicators developed using secondary data to create five dimensions of community culture: engagement with education and employment; social cohesion; feminine and caring activities; adherence to social rules; and collective activities (see the Online Appendix for further details).To match with the personality trait data the community culture data is captured from 2010 and 2011.

\section{Psychocultural Profiling and Economic Performance}

As already indicated, there are potentially bi-directional relationships between community culture and personality traits. For example, it is expected that certain types of community culture will lead to a greater presence of individuals with particular personality traits through both social pressure and selection via migration, and similarly personality traits will play a role in shaping the development of community culture. It is also likely that particular aspects of community culture will complement one another, as will particular personality dimensions. With the current dataset it is not possible to disentangle whether the personality traits present have led to a particular community culture developing or whether the underlying community culture has attracted particular personality types. However, it is predicted that certain combinations of community culture aspects and personality traits will develop together. These forms of psycho-cultural behaviour are what this study focuses on. 
Given the lack of existing work that indicates the type of behaviour that may form, an exploratory Principal Components Analysis (PCA) analysis is applied to identify the forms of psychocultural behaviour present in Great Britain. This process identifies the common variance in the community culture and personality variables across localities, allowing a determination of those combinations of community culture and personality that are likely to coexist within localities. The number of aggregate forms of psychocultural behaviour extracted is determined by the Kaiser criterion of selecting those components with Eigenvalues of 1 or greater. In order to generate more easily definable psycho-cultural forms of behaviour a varimax rotation is used. The Anderson-Rubin approach is used to generate non-correlated scores to lessen issues of collinearity when conducting multivariate analysis.

The study utilises both bivariate and multivariate approaches to analyse the relationship between GVA and GDHI growth with the psycho-cultural behaviour variables created. Initially, correlation statistics are used to analyse any relationships between the psychocultural behaviour variables generated from the PCA and local economic growth rates. Given that economic growth in a locality is likely to be affected by a number of other factors it is necessary to determine whether the psycho-cultural behaviour measures are significantly related to growth or whether those localities with particular characteristics are also those with other characteristics associated with growth. In particular, the study draws upon the literature that has examined the convergence of national or regional economies (Breinlich, Ottaviano, and Temple, 2014). Given the assumptions of diminishing returns to inputs such as labour and capital and that no other factors play a role, it expected that weaker localities will grow more quickly than stronger localities as they converge to a common steady state growth rate (Barro and Sala-i-Martin, 1991). To capture this the following relationships are estimated:

$\left(y_{i t}-y_{i t-\tau}\right) / \tau=\alpha+\beta y_{i t-\tau}+\delta p c_{i}+\vartheta x_{i t-\tau}+\varepsilon_{i t}$ 
where the left hand side captures the growth rate for locality i's economic success measure $\left(y_{i t}\right)$ as captured by the log of either GVA or GDHI, over the period $t-\tau$ to $t$. Convergence will be captured by the term $\beta$, which is expected to reflect a negative relationship with the economic success of the locality in period $t-\tau$. However, given the mobility of labour and capital between cities, localities and regions this may not hold with some places benefiting from increasing process of specialisation and agglomeration (Storper, 2010). There are studies at the county and regional level in the UK that suggest there is little evidence of convergence and potentially divergence (Roberts, 2004). Others suggest both divergence and convergence occur depending on the national economic conditions, with convergence during recessions and divergence during booms (Dewhurst, 1998). The influence of the psychocultural measures $\left(p c_{i}\right)$ are captured by coefficient $\delta$. Other structural influences on the growth rate are also controlled for $\left(x_{i}\right)$.

Without other controls Barro and Sala-i-Martin’s (1991) approach would assume that the steady state of growth is consistent across all regions or nations being examined, but Gennaioli et al. (2014) find that controlling for regional fixed effects increases convergence. In other words there is conditional convergence to different steady states of growth after controlling for the characteristics of regional or local economies. The psychocultural variables could influence these differences as captured in equation (1) above, but as well as examining the direct influence of the psycho-cultural measures on economic success, the study also examines whether these local attributes influence the convergence/divergence relationship. This allows for the possibility that particular cultures or personality traits may influence opportunity perception/exploitation (Wyrwich, 2015) or ability to withstand shocks (Huggins and Thompson, 2015b). This requires an interaction of the psychocultural variables with the initial economic success measure: 
$\left(y_{i t}-y_{i t-\tau}\right) / \tau=\alpha+\beta_{1} y_{i t-\tau}+\delta p c_{i}+\beta_{2} y_{i t-\tau} \cdot p c_{i}+\vartheta x_{i t-\tau}+\varepsilon_{i t}$

For the purpose of simplicity and clarity, the individual psychocultural variables are interacted with the initial level of economic success in separate specifications.

\section{Control Variables}

Following Barro and Sal-i-Martin (1991) we control for the initial employment structure by including a measure of employment within key sectors. It is not possible to fully disaggregate localities' employment due to missing data quickly becoming a severe problem. Therefore, a variable capturing the proportion of employment in the manufacturing sector is included (Power et al., 2010). A variable is also included to capture the proportion of employment in the finance sector, given its association with rapid growth and role in the Great Recession (Gardiner et al., 2013).

A further control is included for population density to capture the effects of agglomeration (Storper, 2010). Finally, to complement the measures on psychocultural behaviour a variable is included to capture the quality of more formal institutions. The measure used follows Huggins and Thompson (2016) approach of adjusting Charron et al.’s (2014) EU regional measure of quality of government. This is generated using a combination of the World Bank's Governance Indicators measured at the national level (Kaufmann et al., 2009) and a citizen survey capturing the rating of education, healthcare and law enforcement services at the regional level in terms of their quality, impartiality and corruption. The local level adjustments utilised are based on satisfaction surveys and measures of pressures on these services. 


\section{Results}

Before examining how the socio-spatial community culture and personality psychology variables may combine and evolve together to characterise different localities, it is worth considering the relationships between the variables (Table A1 in the Online Appendix presents the Pearson correlation coefficients for the relevant measures). In general, it appears that different aspects of personality and community culture are related to one another. This is consistent with the previous literature, indicating the routes that the two may follow to influence one another's development, leading to localities that hold particular combinations of complementary personality and community culture traits (Boneva et al., 1998; Hofstede and McCrae, 2004).

PCA is utilised to determine the existence of any combinations of community culture and personality that appear in close association, allowing the identification of psychocultural types. The PCA yield three components extracted with Eigenvalues greater than 1 (Table 1). The first component, which appears to describe a psychocultural behavioural profile that can be termed as 'Inclusive Amenability', as it has high levels of agreeableness, conscientiousness, social cohesion, femininity and caring activities, and adherence to social rules, but low levels of openness. There is also evidence of sticking to social rules, which may attract those who are conscientious to an area or promote such behaviours within the existing population (Bourgeois and Bowen, 2001). This psychocultural behaviour is least evident in Greater London and more prevalent in the North of England, Scotland and South Wales (see Figure A1 - Online Appendix). Higher levels tend to be found in more rural localities such as West Somerset (South West England), with larger urban areas displaying less evidence, which could again reflect selective migration of more ambitious individuals to more dynamic economies (Boneva et al., 1998), or conditioning by the economic conditions (Steel et al., 2008; Jokela et al., 2015). 


\section{PLEASE INSERT TABLE 1 ABOUT HERE}

The second component also displays low openness, high social cohesion, and little evidence of extraversion. However, what is noteworthy is that whilst collective activities are negatively loaded on component 2, which can be termed 'Individual Commitment', this is not the case for component 1 . As well as having a negative loading from collective activities, component 2 also has a large positive loading from engagement with education and employment. It appears that whilst agreeable and conscientious, this psychocultural profile places emphasis on individualism and there is less evidence of caring socially for others. This may be regarded as still encouraging collaboration, but for reward and not altruistic behaviour, potentially rewarding growth, but not necessarily wider well-being (Huggins and Thompson, 2012). This manifests itself as higher levels of individual commitment around London (but not within London) and diminishing towards more peripheral regions such as Scotland (particularly the central belt), Wales (North and South), and the North East of England.

Component 3, termed 'Diverse Extraversion', is positively associated with extraversion, openness and displays low social cohesion. Conscientiousness and adherence to social rules are less evident than in the other two components. Neuroticism is also low. This psychocultural profile might be seen as linked to creativity and innovation, with greater bridging social capital formed (Putnam, 2000; Hauser et al., 2007), and open to new ideas and people (Levie, 2007; Florida et al., 2008). The highest levels found for this last psychocultural behaviour are in parts of London and the M3 and M4 motorway corridors stemming from London. Not all of Greater London has uniformly high levels of this psycho-cultural behaviour, with the east of London displaying lower levels. There are, however, surprisingly higher levels found in some rural areas such as Perth and Kinross in Scotland and Harrogate in Yorkshire and Humber, which may reflect commuter belts for cities such as Edinburgh and 
Leeds respectively. Lower levels of this psycho-cultural behaviour are found in the East Midlands in localities such as Boston, and those around Nottingham such as Gedling.

\section{Economic Growth and Psychocultural Behavioural Profiles}

The previous subsection found that the distribution of personality psychology traits and community culture generate three distinct forms of psychocultural profiles with differing patterns across the British localities. Given the success of the dominant regions of London, the South East, and East of England it may be expected that localities displaying higher levels of Individual Commitment and Diverse Extraversion would be most successful. Individually Committed psychocultural characteristics may promote some activities associated with growth, but suppress others, as it incorporates the higher conscientiousness that Lee (2017) associates with innovation. However, openness is low, whilst adherence to social rules are high, which others suggest would not benefit entrepreneurial activities (Obschonka et al., 2013, 2015; Rentfrow et al., 2015; Huggins and Thompson, 2016). Diverse Extraversion, however, is high in extraversion and openness, low in neuroticism, which are characteristics linked with entrepreneurial cultures (Obschonka et al., 2013, 2015).

Although possibly lowering transaction costs (Beugelsdijk and van Schaik, 2005), inclusive amenable psycho-cultural behaviour may support broader measures of well-being rather than economic growth (Beugelsdijk and Smulders, 2003). It is also important to recognise that localities with this particular psychocultural profile may also enjoy better access to inputs, and it will be necessary to take these into account, although others assert the need to distinguish between the bonding social capital that may be promoted by such a psychocultural profile and bridging social capital that may provide access to more valuable knowledge (Putnam, 2000). 
To obtain an initial understanding of the relationship between the types of psychocultural profile and economic growth, Table A2 in the Online Appendix reports the Pearson correlation coefficients, including the other control variables utilised in the regression analysis. Tables 2 and 3 report the regressions of GVA and GDHI growth respectively for 2002 to 2015 and the three sub-periods. For both sets of regressions the F-tests indicate that the coefficients are collectively significant from zero. The proportion of variance explained varies from 9\% (GVA 2007-11 growth) to over a third (GDHI 2002-15 growth).

\section{PLEASE INSERT TABLE 2 ABOUT HERE}

As shown by Table 2, inclusive amenable behaviour is significantly negatively associated with economic growth for the full period and three sub-periods at the $1 \%$ significant level or better. Given the nature of this psychocultural profile, this may reflect localities where this behaviour is more prevalent placing greater importance on broader non-economic development outcomes. This confirms the need to consider what constitutes development from the perspective of those experiencing it (Pike et al., 2007). It may also be the case that psychocultural behavioural profiles develop to cope with more challenging environments (Steel et al., 2008; Jokela et al., 2015). Interestingly, individually committed behaviour shows a significant negative relationship for the $2007-2011$ pre-recession period $(0.1 \%$ significance). However, for the period as a whole, and the recession period itself, no significant relationship is found. In the period after the recession, the relationship with GVA growth becomes positive. This may reflect a behavioural profile promoting hardworking and tenacious tendencies. This may be particularly important when trying to make the most of opportunities in periods of uncertainty (Lee, 2017). It is also consistent with the finding that conscientiousness is positively linked to long-term survival of businesses (Ciavarella et al., 2004). Diverse extravert behaviour shows a positive and significant relationship for all periods with the exception of the period 2002-2007. Again, this is consistent with those 
studies that note the importance of being open to other individuals and ideas (Florida, 2002a; Levie, 2007). Such a relationship during the recessionary period may reflect the benefits of openness with respect to managing uncertainty (Hodson and Sorrentino, 1999).

The coefficient on initial GVA is negative and insignificant, suggesting that after controlling for other influences on growth there is no convergence between British localities over the period in question. Alongside explanations associated with agglomeration, specialisation and increasing returns (Storper, 2010), the coping mechanisms associated with the inclusive amenable behaviour may boost well-being in those localities with lower wealth (Steel et al., 2008; Jokela et al., 2015). However, they may also become part of the problem in terms of preventing growth in subsequent periods. Interestingly, more rural areas displayed greater growth prior to the recession, which may reflect the legacies of deindustrialisation for many British cities (Power et al., 2010). Understandably, it is those areas with greater labour market exposure to the finance sector that had lower growth during the recession period.

The GDHI growth results in Table 3 present a similar picture to those relating to GVA growth, but with the psychocultural components displaying stronger relationships. This is likely to be reflective of the closer association with the population's economic prosperity, rather than the wealth extracted by employers and their shareholders. When examining the sub-periods, weaker relationships are found during the recessionary period. With the exception of this period, diverse extraversion is associated with stronger growth in GDHI, whilst a more inclusive and amenable psychocultural behavioural pattern appears to limit economic prosperity. In this case, localities may be seeking to achieve different forms of development, but given that Huggins and Thompson (2012) find a positive link between some broader measures of well-being and competitiveness, it is unclear whether these forms of behaviour will achieve positive economic outcomes. This relationship does weaken in the recession, which may reflect a form of behavioural resilience, and as with the results 
presented in Table 2 individual commitment appears to have aided the resilience of local economies in terms of allowing greater bounce-back with regard to economic performance (Martin and Sunley, 2017).

\section{PLEASE INSERT TABLE 3 ABOUT HERE}

Although not reported in full here (but available in the Online Appendix, the estimations were repeated with GVA per capita growth (Table A3) and GDHI per capita growth (Table A4) as the dependent variables. For diverse extraversion and inclusive amenability, similar patterns were found, with the former supporting higher growth and the latter restricting it. To try to account for the influence of commuter patterns, the Online Appendix also includes results when using a restricted sample of travel to work areas. For GVA growth (Table A5) and GVA per capita growth (Table A6) the reduced sample size appears to limit the significance of results. However, in both cases it is again found that individual commitment appears to help localities to recover from recessions, but has a negative relationship in the period prior to the recession, highlighting the that local psychocultural profiles are likely to have differing economic impacts at different times during macroeconomic cycles Equivalent results for GDHI growth (Table A7) and GDHI per capita growth (Table A8), largely repeat the patterns found in earlier the results.

Regressions were also performed whereby the initial GVA and GDHI is interacted with the psychocultural profile variables to GVA and GDHI growth, respectively (Tables A9 and A10 in the Online Appendix). With regard to GVA growth, a positive interaction is found for diverse extraversion, suggesting that higher levels of diverse extraversion may promote a process of divergence. In the case of inclusive amenability, a negative interaction is found, indicating processes that promote conditional convergence. In general the patterns are similar 
for GDHI growth, with diverse extraversion encouraging divergence, and inclusive amenability promotes conditional convergence.

\section{Conclusions}

Rather than study aspects of socio-spatial community culture and personality psychology independently this study, following the call of others, has examined how the community culture and personality traits of localities holistically combine in the form of local psychocultural profiles that influence the economic growth experienced by these localities (Rentfrow et al., 2013). The study initially set out to ascertain whether there are any relationships present between community culture dimensions and personality traits. Complementary community cultures and personality traits reinforce one another to create quite distinct psychocultural behaviour profiles (Boneva et al., 1998; Hofstede and McCrae, 2004; Rentfrow et al., 2013). Three forms of psychocultural behavioural profile are identified. Whilst one, Diverse Extraversion, displays lower levels of social cohesion and neuroticism and higher levels of extraversion and openness, the other psychocultural profiles display higher levels of agreeableness, social cohesion and collective traits - defined as Inclusive Amenability - or independent and self-sufficient characteristics, defined as Individual Commitment.

Although individual aspects of community culture and personality psychology traits have been linked to local economic activities and growth (Huggins and Thompson, 2015a; Obschonka et al., 2015; Stuetzer et al., 2016), they may be even more strongly influenced by the combinations that generate specific forms of a holistic psychocultural behavioural profile (Rentfrow et al., 2013). In particular, inclusive amenable and individually committed psychcultural profiles appears to hold back growth, particularly in the periods prior to and 
after recessions. However, during the recessions there is less evidence of this, with inclusive amenable traits not appearing to be negatively associated with growth.

Overall, the results appear to provide support for advocates of more competitive freer market approaches to society and the economy in the form of diverse and extravert behaviour. The alternative forms of psychocultural behavioural profile - inclusive amenability and individual commitment - are generally negatively associated with rising living standards during periods of national economic growth. However, during the recessionary period, this relationship largely disappears, and after the recession was reversed for individual commitment, consistent with properties of resilience in the form of bounce-back (Martin and Sunley, 2017). Equally, inclusive amenability was found to promote conditional convergence, suggestive of such psychocultural behaviour being more appropriate for struggling regions.

With regard to policies for promoting local economic, growth, engineering a particular psychocultural behavioural profile is clearly not something that policy makers can achieve overnight. However, the education system could be used to encourage the development of individuals more willing to express themselves, question rules and be open to new ideas. Such programmes could be embedded within citizenship and creativity elements of the curriculum, although there are debates concerning whether citizenship classes are already trying to achieve too wide a spectrum of results (Tonge, Mycock, Jeffery, 2012). Studies on entrepreneurship education have often advocated the use of entrepreneurs to act as role models (Kwong et al., 2012); however, the evidence presented here suggests that such a role should focus of different aspects in different locations. Where diverse extravert behaviour is more prevalent, the importance of organisation and work ethic may be emphasised, whilst in areas of high individual commitment the creative and rule breaking aspects might be the focus. Fundamentally, different psychocultural behavioural profiles are likely encourage different forms of development, policymaking should, as far as possible, account for both. 
Indeed, this study has shown that grand visions to reinvigorate large national economies such as UK are unlikely to be successful if they are not tailored for the particular psychocultural behavioural profiles of local populations. It has also indicated that it is not necessarily individual personality traits or community culture components that are important, but the holistic psychocultural behavioural profile that stems from these components.

Finally, this study does have limitations that future research is advised to explore and account for in more depth. Like most studies that incorporates the geography of personality, the study utilises the mean values for the personality traits. However, the distribution of personality traits may also be of importance (Mathieu et al., 2014), and future studies should seek to explore the dispersion of personality traits. This aligns with research that has examined the impact of personality fit on well-being (Jokela et al., 2015). For example, given the importance of openness and diversity, there is an implication that localities may not just benefit from having greater diverse extraversion per se, but in the way this diverse extraversion also allows the flourishing of other forms of behaviour through greater tolerance (Florida, 2002a; 2002b). Other directions for future research would be to develop longitudinal datasets of personality to help examine the coevolution of culture and personality with more causal clarity.

\section{References}

Adler PS, Kwon S-W (2000) Social capital: the good, the bad, and the ugly. In: Lesser E L (ed.) Knowledge and Social Capital: Foundations and Applications. Boston, MA: Butterworth Heinemann, pp. 89-115.

Aghion P, Alesina A and Trebbi F (2004) Endogenous political institutions. Quarterly Journal of Economics 119(2): 565-612.

Barca F, McCann P and Rodríguez-Pose A (2012) The case for regional development intervention: place-based versus place-neutral approaches. Journal of Regional Science 52(1): 134-152.

Barro RJ and Sala-i-Martin X (1991) Convergence across states and regions. Brookings Papers on Economic Activities 1: 107-182. 
Beugelsdijk S and Smulders S (2003) Bonding and bridging social capital: which type is good for economic growth?. In: Arts W, Halman L and Hagenaars J (eds) The Cultural Diversity of European Unity: Findings, Explanations and Reflections from the European Values Study. Boston, MA: Brill Leiden, pp. 147-184.

Beugelsdijk S and van Schaik T (2005) Differences in social capital between 54 Western European regions. Regional Studies 39(8): 1053-1064.

Bjørnskov C (2006) The multiple facets of social capital. European Journal of Political Economy 22(1): 22-40.

Boneva BS, Frieze IH, Ferligoj A, Jaršová E, Pauknerová D and Orgocka A (1998) Achievement, power, and affiliation motives as clues to emigration desires: a four-countries comparison. European Psychologist 3(4): 247-254.

Bourgeois MJ and Bowen A (2001) Self-organization of alcohol-related attitudes and beliefs in a campus housing complex: an initial investigation. Health Psychology 20(6): 434-437.

Breinlich H, Ottaviano GIP and Temple JRW (2014) Regional growth and regional decline. In: Aghion P and Durlauf SN (eds) Handbook of Growth, Vol. 2B. Oxford: Elsevier, pp. 683779 .

Bristow G and Healy A (2014) Regional resilience: an agency perspective. Regional Studies 48(5): 923-935.

Caspi A (2000) The child is father of the man: personality continuities from childhood to adulthood. Journal of Personality and Social Psychology 78(1): 158-172.

Cattell RB (1943) The description of personality: basic traits resolved into clusters. Journal of Abnormal and Social Psychology 38(4): 476-506.

Chapman BP and Goldberg LR (2011) Replicability and 40 year predictive power if childhood ARC types. Journal of Personality and Social Psychology 101(3): 593-606.

Charron N, Dijkstra L and Lapuente V (2014) Regional governance matters: quality of Government with European Union member states. Regional Studies 48(1): 68-90.

Ciavarella MA, Buchholtz AK, Riordan CM, Gatewood RD and Stokes GS (2004) The Big Five and venture survival: is there a linkage? Journal of Business Venturing 19(4): 465-483.

Cobb-Clark DA and Schurer S (2012) The stability of big-five personality traits. Economic Letters 115(1): 11-5.

Coleman J (1988) Social capital in the creation of human capital. American Journal of Sociology 94(Supplement): S95-S120.

Cooke P, Clifton N and Oleaga M (2005) Social capital, firm embeddedness and regional development. Regional Studies 39(8): 1065-1077.

Costa Jr, PT and McCrae RR (1992) Revised NEO personality inventory (NEO-PI-R) and NEO five -factor inventory (NEO-FFI) professional manual. Odessa, FL: Psychological Assessment Resources. 
Credé M, Harms P, Niehorster S and Gaye-Valentine A (2012) An evaluation of the consequences of using short measures of the Big Five personality traits. Journal of Personality and Social Psychology 102(4): 874-888.

Crespo Cuaresma J, Doppelhofer G and Feldkircher M (2014) The determinants of economic growth in European regions. Regional Studies 48(1): 44-67.

Dasgupta P (2011) A matter of trust : social capital and economic development. In: Lin JY and Pleskovic B (eds) Annual Bank Conference on Development Economics (ABCDE) Global 2010: Lessons from East Asia and the Global Financial Crisis. Washington, DC: World Bank, pp. 119-155.

Davidsson P and Wiklund J (1997) Values, beliefs and regional variations in new firm formation rates. Journal of Economic Psychology 18(2/3): 179-199.

Dewhurst JHL (1998) Convergence and divergence in regional household incomes per head in the United Kingdom, 1984-93. Applied Economics 30(1): 31-35.

Easterly W, Ritzen J and Woolcock M (2006) Social cohesion, institutions, and growth. Economics and Politics 18(2): 103-120.

Florida R (2002a) The Rise of the Creative Class and How It's Transforming Work, Life, Community and Everyday Life. New York, NY: Basic Books.

Florida R (2002b) Bohemia and economic geography. Journal of Economic Geography 2(1): 55-71.

Florida R, Mellander C and Stolarick K (2008) Inside the black box of regional development - human capital, the creative class and tolerance. Journal of Economic Geography 8(5): 615659.

Gardiner B, Martin R, Sunley P and Tyler P (2013) Spatially unbalanced growth in the British economy. Journal of Economic Geography 13(6): 889-928.

Gennaioli N, La Porta R, Lopez De Silanes F and Schleifer A (2014) Growth in regions. Journal of Economic Growth 19(3): 259-309.

Gorodnichenko Y and Roland G (2016) Culture, institutions and the wealth of nations. Review of Economics and Statistics 99(3): 402-416.

Gradstein M and Justman M (2000) Human capital, social capital, and public schooling. European Economic Review 44(4-6): 879-889.

Guiso L, Sepienza P and Zingales L (2004) The role of social capital in financial development. American Economic Review 94(3): 526-56.

Guiso L, Sapienza P and Zingales L (2008) Long term persistence. NBER Working Paper, \#14278.

Hart D, Atkins R and Fegley S (2003) Personality and development in childhood: a personcentred approach. Monographs of the Society for Research in Child Development 68(1): i122. 
Hauser C, Tappeiner G and Walde J (2007) The learning region: the impact of social capital and weak ties on innovation. Regional Studies 41(1): 75-88.

Hodson G and Sorrentino RM (1999) Uncertainty orientation and the Big Five personality structure. Journal of Research in Personality 33(2): 253-261.

Hofstede G (1980) Culture's consequences: Internal differences in work related values. Beverly Hills, CA: Sage.

Hofstede G and McCrae RR (2004) Personality and culture revisited: linking traits and dimensions of culture. Cross-Cultural Research 38(1): 52-88.

Huggins R and Thompson P (2012) Well-being and competitiveness: are the two linked at a place-based level?. Cambridge Journal of Regions, Economy and Society 5(1): 45-60.

Huggins R and Thompson P (2014) Culture, entrepreneurship and uneven development: a spatial analysis. Entrepreneurship and Regional Development 26(9/10), 726-752.

Huggins R and Thompson P (2015a) Culture and place-based development: a socio-economic analysis. Regional Studies 49(1): 130-59.

Huggins R and Thompson P (2015b) Local entrepreneurial resilience and culture: the role of social values in fostering economic recovery. Cambridge Journal of Regions, Economy and Society 8(2): 313-30.

Huggins R and Thompson P (2016) Socio-Spatial Culture and Entrepreneurship: Some Theoretical and Empirical Observations. Economic Geography 92(3): 269-300.

Huggins R and Thompson P (2017) The behavioural foundations of urban and regional development: culture, psychology and agency. Journal of Economic Geography, doi:10.1093/jeg/lbx040.

Hwang H and Powell WW (2005) Institutions and entrepreneurship. In: Alvarez SA, Agarwal $\mathrm{R}$ and Sorenson $\mathrm{O}$ (eds) Handbook of Entrepreneurship Research: Interdisciplinary Perspectives. New York, NY: Springer, pp. 201-232.

John OP, Naumann LP and Soto CJ (2008) Paradigm shift to the integrative Big Five taxonomy: history, measurement and conceptual issues. In: John OP, Robins RW and Pervin LA (eds) Handbook of Personality: Theory and Research. New York, NY: Guilford Press, pp. 114-158.

John OP and Srivastava S (1999) The big five trait taxonomy: history, measurement, and theoretical perspectives. In John OP and Pervin LA (eds) Handbook of Personality: Theory and Research. New York, NY: Guilford Press, pp. 102-138.

Jokela M, Bleidorn W, Lam ME, Gosling SD and Rentfrow PJ (2015) Geographically varying associations between personality and life satisfaction in the London metropolitan area. Proceedings of the National Academy of Sciences of the United States of America 112(3): 725-730.

Jokela M, Elovainio M, Kivimäki M and Keltikangas-Järtvinen L (2008) Temperament and migration patterns in Finland. Psychological Science 19(9): 831-37. 
Judge TA, Higgins CA, Thoresen CJ and Barrick MR (1999) The big five personality traits, general mental ability, and career success across the life span. Personnel Psychology 52(3): 621-52.

Kaufmann D, Kraay A and Mastruzzi M (2009) Governance matters VIII: Aggregate and individual governance indicators for 1996-2008. Policy Research Paper 4978. Washington, DC: World Bank.

Knack S and Keefer P (1997) Does social capital have an economic impact? A cross-country payoff. Quarterly Journal of Economics 112(4): 1251-1288.

Kwon SW and Adler PS (2014) Social capital: maturation of a field of research. Academy of Management Review 39(4): 412-422.

Kwong CCY, Thompson P, Cheung CW-M and Manzoor H (2012) The role of environment in fostering conductive entrepreneurial learning: teaching the 'art' of entrepreneurship in boot camps. Journal of General Management 38(1): 45-71.

Lee ND (2017) Psychology and the geography of innovation. Economic Geography 93(2): 106-130.

Levie J (2007) Immigration, in-migration, ethnicity and entrepreneurship in the United Kingdom. Small Business Economics 28(2): 143-69.

Lippmann S and Aldrich H (2016) A rolling stone gathers momentum: generational units, collective memory, and entrepreneurship. Academy of Management Review 41(4): 658-675.

Martin R and Sunley P (2015) On the notion of regional economic resilience: conceptualization and explanation. Journal of Economic Geography 15(1): 1-42.

Martin R and Sunley P (2017) Competitiveness and regional economic resilience. In: Huggins R and Thompson P (eds) Handbook of Regions and Competitiveness: Contemporary Theories and Perspectives on Economic Development. Cheltenham: Edward Elgar, pp. 287307.

Mathieu JE, Tannenbaum SI, Donsbach JS and Alliger GM (2014) A review and integration of team composition models: moving toward a dynamic and temporal framework. Journal of Management 40(1): 130-160.

Murphy L, Huggins R and Thompson P (2016) Social capital and innovation: a comparative analysis of regional policies. Environment and Planning C 34(6): 1025-1057.

North DC (1990) Institutions, institutional change and economic performance. Cambridge: Cambridge University Press.

Obschonka M, Schmitt-Rodermund E, Gosling SD and Silbereisen RK (2013) The regional distribution and correlates of an entrepreneurship-prone personality profile in the United States, Germany, and the United Kingdom: a socioecological perspective. Journal of Personality and Social Psychology 105(1): 104-122.

Obschonka M, Stuetzer M, Audretsch DB, Rentfrow PJ, Potter J and Gosling SD (2016) Macropsychological factors predict regional economic resilience during a major economic crisis. Social Psychological and Personality Science 7(2): 95-104. 
Obschonka M, Stuetzer M, Gosling SD, Rentfrow PJ, Lamb ME, Potter J and Audretsch DB (2015) Entrepreneurial regions: do macro-psychological cultural characteristics of regions help solve the "knowledge paradox" of economics?. PLoS ONE 10(6). doi: 10.1371/journal.pone.0129332

Pettigrew TF and Tropp LR (2006) A meta-analytical test of intergroup contact theory. Journal of Personality and Social Psychology 90(5): 751-783.

Pike A, MacKinnon D, Cumbers A, Dawley S and McMaster R (2016) Doing evolution in economic geography? Economic Geography 92(2): 123-144.

Pike A, Rodríguez-Pose A and Tomaney J (2007) What kind of local and regional development and for whom?. Regional Studies 41(9): 1253-1269.

Power A, Plöger J and Winkler A (2010) Phoenix Cities. Bristol: Policy Press.

Putnam R (2000) Bowling Alone: The Collapse and Revival of American Community. New York, NY: Simon and Schuster.

Putnam RD, Leonardi R and Nanetti RY (1993) Making Democracy Work: Civic Traditions in Modern Italy. Princeton, NJ: Princeton University Press.

Rauch A, Frese M, Wang Z-M, Unger J, Lozada M, Kupcha V and Spirina T (2013) National culture and cultural orientations of owners affecting the innovation-growth relationship in five countries. Entrepreneurship and Regional Development 25(9/10): 732-755.

Rentfrow PJ (2010) Statewide differences in personality: toward a psychological geography of the United States. American Psychologist 65(6): 548-558.

Rentfrow PJ, Gosling SD, Jokela M, Stillwell DJ, Kosinski M and Potter J (2013) Divided we stand: three psychological regions of the United States and their political, economic, social and health correlates. Journal of Personality and Social Psychology 105(6): 996-1012.

Rentfrow PJ, Gosling SD and Potter J (2008) A theory of the emergence, persistence, and expression of geographical variation in psychological characteristics. Perspectives on Psychological Science 3(5): 339-369.

Rentfrow PJ, Jokela M and Lamb ME (2015) Regional personality differences in Great Britain. PLoS ONE 10(3): doi: 10.1371/journal.pone.0122245

Rentfrow PJ, Jost JT, Gosling SD and Potter J (2009) Statewide differences in personality predict voting patterns in 1996-2004 U.S. presidential elections. In: Jost JT, Kay AC and Thorisdottir H (eds) Social and Psychological Bases of Ideology and System Justification. Oxford: Oxford University Press, pp.314-350.

Roberts M (2004) The growth performances of the GB countries: some new empirical evidence for 1977-1993. Regional Studies 38(2): 149-165.

Rodríguez-Pose A (2001) Local production systems and economic performance in Britain, France, Germany, and Italy. In: Crouch C, Le Galès P, Trigilia C and Voelzkow H (eds) Local Production Systems in Europe. Rise or Demise?. Oxford: Oxford University Press, pp. 25-45. 
Rodríguez-Pose A and Hardy D (2015) Cultural diversity and entrepreneurship in England and Wales. Environment and Planning A 47(2): 392-411.

Rodríguez-Pose A and Storper M (2006) Better rules or stronger communities? On the social foundations of institutional change and its economic effects. Economic Geography 52(1): 125.

Rutten R and Boekema F (2007) Regional social capital: embeddedness, innovation networks and regional economic development. Technological Forecasting and Social Change 74(9): 1834-1846.

Rutten R and Boekema F (2012) From learning region to learning in a socio-spatial context. Regional Studies 46(8): 981-992.

Schmitt DP, Allik J, McCrae RR and Benet-Martínez V (2007) The geographical distribution of big five personality traits: patterns and profiles of human self-description across 56 nations. Journal of Cross-Cultural Psychology 38(2): 173-212.

Scott WR (2008) Institutions and Organizations. Thousand Oaks, CA: Sage.

Steel P, Schmidt J and Shultz J (2008) Refining the relationship between personality and subjective well-being. Psychological Bulletin 134(1): 138-161.

Storper M (2010) Why does a city grow? Specialisation human capital or institutions?. Urban Studies 47(10): 2027-2050.

Storper M (2013) Keys to the City: How Economics, Institutions, Social Interaction, and Politics Shape Development. Princeton, NJ: Princeton University Press.

Stuetzer M, Obschonka M, Audretsch DB, Wyrwich M, Rentfrow PJ, Coombes M, ShawTaylor L and Satchell M (2016) Industry structure, entrepreneurship, and culture: an empirical analysis using historical coalfields. European Economic Review 86(1): 52-72.

Tabellini G (2010) Culture and institutions: economic development in the regions of Europe. Journal of the European Economic Association 8(4): 677-716.

Tonge J, Mycock A and Jeffery B (2012) Does citizenship education make young people better-engaged citizens? Political Studies 60(3): 578-602.

Tubadji A and Nijkamp P (2015a) Cultural gravity effects among migrants: a comparative analysis of the EU15. Economic Geography 91(3), 343-380.

Tubadji A and Nijkamp P (2015b) Cultural impact on regional development: application of a PLS-PM model to Greece. Annals of Regional Science 54(3): 687-720.

Tupes EC and Christal RE (1961) Recurrent personality factors based on trait ratings, Technical Report ASD-TR-61-97. Lackland, TX: Personnel Laboratory Aeronautical Systems Division Air Force Systems Command Lackland Air Force Base.

Van de Vliert E (2009) Climate, affluence, and culture. Cambridge: Cambridge University Press.

Van den Berg JC and Stagl S (2003) Coevolution of economic behaviour and institutions: towards a theory of institutional change. Journal of Evolutionary Economics 13(3): 289-317. 
Van Maanen J and Schein EH (1979) Toward a theory of organizational socialization. Rese arch In Organizational Behavior 1(1): 209-264.

Wyrwich M (2015) Entrepreneurship and the intergenerational transmission of values. Small Business Economics 45(1): 191-213.

Zak P and Knack S (2001) Trust and growth. Economic Journal 111(470): 295-321. 
Table 1: Principal Components Analysis Rotated Component Matrix of Socio-Spatial Community Culture and Personality PsychologyVariables

\begin{tabular}{lcccc}
\hline & $\begin{array}{c}\text { Psychocultural Profile: } \\
\text { Inclusive Amenability }\end{array}$ & $\begin{array}{c}\text { Psychocultural } \\
\text { Profile: Individual } \\
\text { Commitment }\end{array}$ & $\begin{array}{c}\text { Psychocultural } \\
\text { Profile: Diverse } \\
\text { Extraversion }\end{array}$ & $\begin{array}{c}\text { Extracted } \\
\text { Variance }\end{array}$ \\
\hline Extraversion & -0.299 & 0.068 & 0.807 & 0.745 \\
Agreeableness & 0.833 & -0.059 & 0.129 & 0.713 \\
Conscientiousness & 0.679 & 0.548 & 0.145 & 0.781 \\
Neuroticism & -0.269 & -0.276 & -0.824 & 0.827 \\
Openness & -0.570 & -0.222 & 0.509 & 0.633 \\
Engagement with Education & 0.112 & 0.832 & -0.014 & 0.705 \\
Social Cohesion & 0.838 & -0.066 & -0.322 & 0.810 \\
Femininity and Caring & 0.757 & 0.194 & -0.153 & 0.634 \\
Adherence to Social Rules & 0.584 & 0.577 & 0.085 & 0.682 \\
Collective Activities & 0.080 & -0.877 & -0.194 & 0.813 \\
Unrotated & & & & 1.125 \\
Eigenvalues & 3.865 & 2.352 & 11.3 & \\
Percentage of Variance & 38.7 & 23.5 & & 1.798 \\
Rotated & & & 18.0 & \\
Eigenvalues & 3.275 & 2.270 & & \\
Percentage of Variance & 32.8 & 22.7 & & \\
\hline
\end{tabular}


Table 2: Regressions of Local Authority District GVA Growth

\begin{tabular}{|c|c|c|c|c|}
\hline & 2002 to 2015 & 2002 to 2007 & 2007 to 2011 & 2011 to 2015 \\
\hline Initial GVA & $\begin{array}{l}-0.0002 \\
(0.805)\end{array}$ & $\begin{array}{l}-0.0016 \\
(0.382)\end{array}$ & $\begin{array}{l}0.0009 \\
(0.644)\end{array}$ & $\begin{array}{r}-0.0015 \\
(0.384)\end{array}$ \\
\hline Diverse Extraversion & $\begin{array}{c}0.0010^{\dagger} \\
(0.073)\end{array}$ & $\begin{array}{l}-0.0015 \\
(0.138)\end{array}$ & $\begin{array}{c}0.0031^{* *} \\
(0.004)\end{array}$ & $\begin{array}{c}0.0022 * \\
(0.027)\end{array}$ \\
\hline Inclusive Amenability & $\begin{array}{c}-0.0042^{* * *} \\
(0.000)\end{array}$ & $\begin{array}{c}-0.0038^{* *} \\
(0.003)\end{array}$ & $\begin{array}{c}-0.0051 * * * \\
(0.001)\end{array}$ & $\begin{array}{c}-0.0046 * * * \\
(0.001)\end{array}$ \\
\hline Individual Commitment & $\begin{array}{l}-0.0002 \\
(0.753)\end{array}$ & $\begin{array}{c}-0.0038^{* * *} \\
(0.000)\end{array}$ & $\begin{array}{l}0.0014 \\
(0.204)\end{array}$ & $\begin{array}{c}0.0027^{* *} \\
(0.005)\end{array}$ \\
\hline Quality of Government & $\begin{array}{l}-0.0014 \\
(0.497)\end{array}$ & $\begin{array}{l}-0.0039 \\
(0.308)\end{array}$ & $\begin{array}{l}-0.0011 \\
(0.807)\end{array}$ & $\begin{array}{l}0.0016 \\
(0.679)\end{array}$ \\
\hline Population Density & $\begin{array}{c}-0.0013^{* *} \\
(0.005)\end{array}$ & $\begin{array}{c}-0.0027^{* *} \\
(0.002)\end{array}$ & $\begin{array}{l}-0.0007 \\
(0.499)\end{array}$ & $\begin{array}{l}-0.0001 \\
(0.910)\end{array}$ \\
\hline Employment in Manufacturing & $\begin{array}{l}0.0010 \\
(0.415)\end{array}$ & $\begin{array}{l}0.0021 \\
(0.346)\end{array}$ & $\begin{array}{l}0.0004 \\
(0.881)\end{array}$ & $\begin{array}{l}0.0017 \\
(0.371)\end{array}$ \\
\hline Employment in Finance & $\begin{array}{l}-0.0003 \\
(0.736)\end{array}$ & $\begin{array}{l}0.0022 \\
(0.153)\end{array}$ & $\begin{array}{c}-0.0041^{*} \\
(0.014)\end{array}$ & $\begin{array}{l}0.0020 \\
(0.165)\end{array}$ \\
\hline Constant & $\begin{array}{l}0.0253 \\
(0.219)\end{array}$ & $\begin{array}{l}0.0698 \\
(0.070)\end{array}$ & $\begin{array}{l}-0.0194 \\
(0.660)\end{array}$ & $\begin{array}{l}0.0479 \\
(0.214)\end{array}$ \\
\hline$N$ & 374 & 374 & 374 & 374 \\
\hline $\begin{array}{l}\text { F-test } \\
p \text {-value }\end{array}$ & $\begin{array}{c}5.62 \\
(0.000)\end{array}$ & $\begin{array}{c}4.86 \\
(0.000)\end{array}$ & $\begin{array}{c}4.48 \\
(0.000)\end{array}$ & $\begin{array}{c}4.98 \\
(0.000)\end{array}$ \\
\hline$R^{2}$ & 0.110 & 0.096 & 0.089 & 0.098 \\
\hline Adjusted $R^{2}$ & 0.090 & 0.076 & 0.069 & 0.079 \\
\hline Akaike Information Criterion & -2473.8 & -2007.3 & -1920.8 & -2013.0 \\
\hline Schwartz Information Criterion & -2438.5 & -1972.0 & -1885.5 & -1977.6 \\
\hline
\end{tabular}


Table 3: Regressions of Local Authority District Gross Disposable Household Income (GDHI) Growth

\begin{tabular}{|c|c|c|c|c|}
\hline & 2002 to 2015 & 2002 to 2007 & 2007 to 2011 & 2011 to 2015 \\
\hline Initial GDHI & $\begin{array}{c}-0.0014^{*} \\
(0.022)\end{array}$ & $\begin{array}{c}-0.0028^{* *} \\
(0.003)\end{array}$ & $\begin{array}{l}0.0002 \\
(0.818)\end{array}$ & $\begin{array}{r}-0.0009 \\
(0.428)\end{array}$ \\
\hline Diverse Extraversion & $\begin{array}{c}0.0016 * * * \\
(0.000)\end{array}$ & $\begin{array}{c}0.0020 * * * \\
(0.000)\end{array}$ & $\begin{array}{l}-0.0004 \\
(0.387)\end{array}$ & $\begin{array}{c}0.0029 * * * \\
(0.000)\end{array}$ \\
\hline Inclusive Amenability & $\begin{array}{c}-0.0042^{* * *} \\
(0.000)\end{array}$ & $\begin{array}{c}-0.0061^{* * *} \\
(0.000)\end{array}$ & $\begin{array}{c}-0.0014^{*} \\
(0.020)\end{array}$ & $\begin{array}{c}-0.0042^{* * *} \\
(0.000)\end{array}$ \\
\hline Individual Commitment & $\begin{array}{c}0.0005 \dagger \\
(0.085)\end{array}$ & $\begin{array}{r}-0.0002 \\
(0.678)\end{array}$ & $\begin{array}{l}-0.0006 \\
(0.208)\end{array}$ & $\begin{array}{c}0.0026 * * * \\
(0.000)\end{array}$ \\
\hline Quality of Government & $\begin{array}{l}-0.0010 \\
(0.394)\end{array}$ & $\begin{array}{l}-0.0030 \\
(0.115)\end{array}$ & $\begin{array}{l}0.0028 \\
(0.140)\end{array}$ & $\begin{array}{c}-0.0026 \\
(0.228)\end{array}$ \\
\hline Population Density & $\begin{array}{c}-0.0010^{* * *} \\
(0.000)\end{array}$ & $\begin{array}{c}-0.0021 * * * \\
(0.000)\end{array}$ & $\begin{array}{c}-0.0015^{* * *} \\
(0.001)\end{array}$ & $\begin{array}{c}0.0011^{*} \\
(0.020)\end{array}$ \\
\hline Employment in Manufacturing & $\begin{array}{r}-0.0005 \\
(0.450)\end{array}$ & $\begin{array}{r}-0.0015 \\
(0.181)\end{array}$ & $\begin{array}{r}-0.0001 \\
(0.959)\end{array}$ & $\begin{array}{l}-0.0010 \\
(0.329)\end{array}$ \\
\hline Employment in Finance & $\begin{array}{r}-0.0002 \\
(0.607)\end{array}$ & $\begin{array}{r}-0.0006 \\
(0.446)\end{array}$ & $\begin{array}{l}-0.0001 \\
(0.896)\end{array}$ & $\begin{array}{l}-0.0008 \\
(0.327)\end{array}$ \\
\hline Constant & $\begin{array}{c}0.0275^{* * *} \\
(0.000)\end{array}$ & $\begin{array}{c}0.0615^{* * *} \\
(0.000)\end{array}$ & $\begin{array}{l}-0.0001 \\
(0.993)\end{array}$ & $\begin{array}{l}0.0134 \\
(0.152)\end{array}$ \\
\hline$N$ & 374 & 374 & 374 & 374 \\
\hline $\begin{array}{l}\text { F-test } \\
p \text {-value }\end{array}$ & $\begin{array}{c}24.75 \\
(0.000)\end{array}$ & $\begin{array}{c}17.51 \\
(0.000)\end{array}$ & $\begin{array}{c}1.96 \\
(0.051)\end{array}$ & $\begin{array}{c}22.44 \\
(0.000)\end{array}$ \\
\hline$R^{2}$ & 0.352 & 0.277 & 0.041 & 0.330 \\
\hline Adjusted $R^{2}$ & 0.337 & 0.262 & 0.020 & 0.315 \\
\hline Akaike Information Criterion & -2896.2 & -2547.0 & -2541.0 & -2434.7 \\
\hline Schwartz Information Criterion & -2860.9 & -2511.7 & -2505.7 & -2399.4 \\
\hline
\end{tabular}

Notes: p-values in parentheses. Coefficients significant at $* * * 0.1$ percent level, ${ }^{* *} 1$ percent level, * 5 percent level, $† 10$ percent level 